\title{
LIP record through time and implications for secular environmental changes and GTS boundaries
}

RICHARD E. ERNST ${ }^{1,2}$, DAVID P.G. BOND ${ }^{3}$, SHUANHONG ZHANG ${ }^{4}$, KENNETH L. BUCHAN ${ }^{5}$, STEPHEN E. GRASBY $^{6}$, NASRRDDINE YOUBI $^{7,8}$, HAFIDA EL BILALI $^{1}$,ANDREY BEKKER ${ }^{9}$, LUC S. DOUCET ${ }^{10}$

${ }^{1}$ Department of Earth Sciences, Carleton University, Canada

${ }^{2}$ Faculty of Geology \& Geography, Tomsk State U. , Russia

${ }^{3}$ Department of Geography, Geology and Environment, University of Hull, Hull, United Kingdom

${ }^{4}$ Institute of Geomechanics, Chinese Academy of Geological Sciences, Beijing, China,

5273 Fifth Ave. Ottawa, ON K1S 2N4, Canada

${ }^{6}$ Geological Survey of Canada, Calgary, Canada

${ }^{7}$ Department of Geology, Cadi Ayyad University, Marrakesh, Morocco

${ }^{8}$ Instituto Dom Luiz, U. de Lisboa, Lisbon, Portugal

${ }^{9}$ Dept. Earth \& Planetary Sc. U. California, Riverside, CA, USA

${ }^{10}$ Earth Dynamics Research Group, TIGeR, School of Earth \& Planetary Sciences, Curtin U., Perth, WA, Australia

An emerging consensus suggests that Large Igneous Provinces (LIPs) are a significant driver of dramatic global environmental and biological changes, including several Phanerozoic mass extinctions, leading to plausible links with Geological Time Scale (GTS) boundaries. LIP-induced environmental changes are now being identified in the Precambrian record, suggesting potential for the use of LIPs to define natural pre-Phanerozoic GTS boundaries. There is now an opportunity for more systematic integration of the sedimentary and LIP records.

As a contribution to assessing the role of LIPs in secular environmental/biological changes and their correlations with the GTS, we provide an updated summary of the LIP record through time in a series of time-slice diagrams and in a data compilation. We also summarize links between LIPs, GTS boundaries and selected environmental impacts.

Continued integration of the LIP and sedimentary records will help to: 1) identify those LIPs that induced major environmental changes and thus can help define chronostratigraphic GTS boundaries, as well as those that had minor, or no observable impact on surface environments; 2) lead to better characterization of the specific components of LIPs that caused secular environmental changes; and 3) allow proper integration of LIP events with other drivers of secular environmental changes such as bolide impacts. 